\title{
Analysis on the Current Situation and Countermeasures of Traffic Integration Development in Beijing, Tianjin and Hebei
}

\author{
Xiaoqi Zhang ${ }^{\mathrm{a}}$, Chuansheng Wang ${ }^{\mathrm{b}}$, Cuiyou Yao ${ }^{\mathrm{c}}$ \\ School of information, Capital University of Economics and Business, Beijing 100070, China \\ a zhxq@cueb.edu.cn, b'wangcs@cueb.edu.cn, c ycy@cueb.edu.cn
}

Keywords: Traffic integration, pioneering area for coordinated development.

\begin{abstract}
The coordinated development of Beijing, Tianjin and Hebei has risen to a major national strategy. Traffic integration, as a pioneering area for coordinated development, plays an important role in promoting urbanization, industrial restructuring and regional coordinated development. Therefore, this paper analyzes the current situation of traffic integration in Beijing, Tianjin and Hebei from the aspects of infrastructure construction, transportation services and investment in fixed assets. Through the analysis of the relevant data, it explores the problems in its development process. On this basis, it puts forward countermeasures and suggestions to promote the integrated development of traffic in Beijing, Tianjin and Hebei.
\end{abstract}

\section{Introduction}

The core of the coordinated development of Beijing, Tianjin and Hebei is to dissolve Beijing's non capital function in an orderly way and adjust the economic and spatial structure. As the artery of the coordinated development of Beijing, Tianjin and Hebei, traffic integration is the inevitable choice to take the lead in achieving the breakthroughs. The "Beijing-Tianjin-Hebei Collaborative Development Plan" and the "Beijing-Tianjin-Hebei Collaborative Development Transportation Integration Plan" have been promulgated one after another to promote the network layout and integrated services of traffic in Beijing, Tianjin and Hebei. At present, Beijing Tianjin and Hebei region has initially formed a radial integrated three-dimensional transportation system centered on Beijing, but there are problems in terms of infrastructure construction, transportation services and institutional mechanisms [1]. Therefore, we should further study the current situation of traffic integration in Beijing, Tianjin and Hebei, and explore the problems in its development process, so as to provide strong transportation support for the coordinated development of Beijing, Tianjin and Hebei.

\section{Literature Review}

In the concept of traffic integration, Zhao J. [2] from the two aspects of integration of traffic planning, construction and transport operators to understand traffic integration. He pointed out that the obstacles of traffic integration come from the aspects of system mechanism and economic development, While the focus of development should be commuter railways. From a system perspective, Pang S H. [3] believes that traffic integration is an integrated transportation system with various modes of transportation and organic combination of transportation resources, covering planning and design, investment and construction, organizational deployment and operation management, etc. Traffic integration is not only the connection of geographical spatial, but also the regional integration of transportation, economy, industry and resources. It is necessary to focus on solving the core functions of non-capitals, making overall plans and promoting them as a whole in order to ease and divert talents and industries [4].

In the study of traffic integration in Beijing, Tianjin and Hebei, domestic scholars have done a lot of research. On the basis of analyzing the advantages and disadvantages of the economic circle of Beijing, Tianjin and Hebei, Wang Z H [5] emphasized the basic role of traffic integration in the economic circle development and believed that the traffic integration goal is according to the needs of economic and social development, to meet the potential mining transportation network, the flow of production factors, to enhance the overall level of implementation of regional transportation. In 
order to achieve this goal, Beijing, Tianjin and Hebei have issued relevant traffic plans one after another, but the traffic planning cooperation among the three places lags behind the concept of regional traffic planning, the lack of a unified traffic planning organization and supervision mechanism, and the lack of synergistic procedures[6]. In response, Zhao $\mathrm{H}$ [7] proposed that the core issue of the coordinated development of Beijing, Tianjin and Hebei should strengthen top-level design and co-ordination. Cheng S D. [8] proposed to optimize the pattern of transportation network, promote the formation of a coordinated transportation development mechanism and improve the transport structure related measures. In addition, under the background of the traffic integration of Beijing, Tianjin and Hebei, Quan B [9, 10] and Yao S Y. [11] respectively studied the modes of traffic development in Beijing, Tianjin and Hebei and put forward the idea of multi-level orbital system layout. Zheng J. [12], Wu T S. [13] and Yuan T. [14] analyzed the railway, aviation and highway in Beijing, Tianjin and Hebei respectively to provide strategic support for the development of transportation in the three places.

\section{Traffic Development in Beijing, Tianjin and Hebei}

The Beijing, Tianjin and Hebei region covers an area of 216,000 square kilometers, accounting for $2.25 \%$ of the national total. After years of hard work, the traffic construction in Beijing, Tianjin and Hebei has made great strides and basically formed an integrated transportation system integrating railways, highways, ports and aviation with a variety of modes of transportation. At the level of transportation facilities development, it is at the leading level in the country, which laid a solid foundation for the coordinated development of Beijing, Tianjin and Hebei [15].

The data source is China Statistical Yearbook 2016, Beijing Statistical Yearbook 2016, Tianjin Statistical Yearbook 2016 and Hebei Statistical Yearbook 2016.

\section{The Current Situation of Infrastructure Construction}

\subsection{Road Construction}

The Beijing, Tianjin and Hebei expressway has Beijing-Harbin, Beijing-Shanghai, BeijingTaiwan, Beijing-Hongkong-Macao, Beijing-Kunming, Beijing-Tibet, Beijing-Urumqi, BeijingKaifeng, Beijing-Chengde, as well as 11 national highways. Among them, Beijing-Tianjin, BeijingHebei, Tianjin-Hebei, have four, six and nine highway interface respectively. The total length of highway and road network density in Beijing, Tianjin and Hebei region showed an increasing trend, and the scale and level of highway construction continued to increase. As of 2015, the total mileage of highways in the region is 223 thousand kilometers, of which 217,000 kilometers are grade roads, accounting for $97.31 \%$ of the total mileage of the highway and 0.84 million kilometers of expressways. The density of highway network is $103.27 \mathrm{~km} / 100$ square kilometers, and the density of expressway network is $3.89 \mathrm{~km} / 100$ square kilometers, which is 2.1 times and 3 times of the national level, respectively, as shown in FIGURE 1. And TABLE 1.

Table 1. Comparison of the density of Beijing-Tianjin-Hebei road and national highway and railway network in 2015 Unit: km / 100 square kilometers

\begin{tabular}{cccc}
\hline Region & Road network density & Highway network density & Railway network density \\
\hline Beijing & 133.46 & 6.09 & 7.92 \\
Tianjin & 138.91 & 9.21 & 8.37 \\
Hebei & 97.75 & 3.33 & 3.71 \\
B-T-H & 103.27 & 3.89 & 4.31 \\
National & 47.7 & 1.28 & 1.26 \\
\hline
\end{tabular}

\subsection{Railway Construction}

The Beijing, Tianjin and Hebei region has formed a radial transportation network featuring Beijing as the core, the Beijing-Shanghai high-speed railway, the Beijing-Guangzhou passenger interchange, the Beijing-Tianjin inter-city as well as the Beijing-Kowloon and Beijing-Harbin railway lines. By 
2015, the railway business mileage reached 9,300 kilometers and the coverage rate of high-speed railways reached nearly $80 \%$. This effectively connects the cities and counties within the Beijing, Tianjin and Hebei region. The railway network density is $4.31 \mathrm{~km} / 100$ square kilometers, which is 3.4 times the national average. However, according to the density of railway network in Beijing, Tianjin and Hebei from 2008 to 2015, it can be found that the railway development in the three areas is not balanced. The railway network density in Beijing and Tianjin is higher, the development of railway network in Hebei is lagging behind and the space for improvement is larger , as shown in FIGURE 2. and TABLE 1.

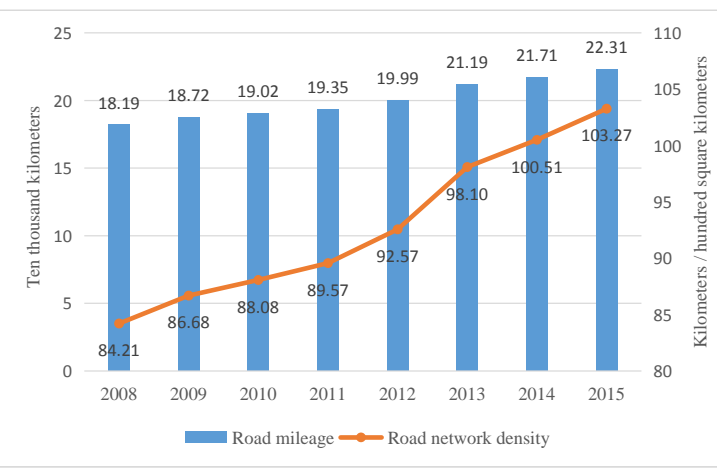

Figure 1. Beijing-Tianjin-Hebei road total mileage and road network density

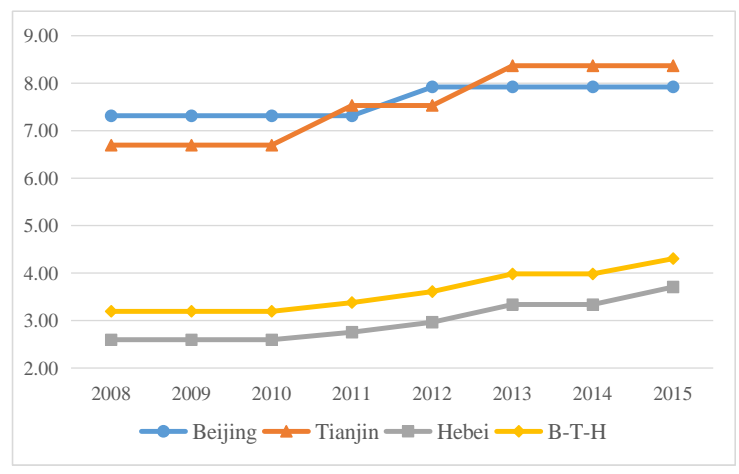

Figure 2. Beijing-Tianjin-Hebei railway network density

\subsection{Port Construction}

There are four coastal ports in the Beijing, Tianjin and Hebei region, including Tianjin Port, Qinhuangdao Port, Huanghua Port and Tangshan Port. There are 510 shipping terminals, of which 375 are above 10,000-tonnage, with an annual cargo throughput of 1,946 billion tons. Tianjin Port is the most comprehensive trade port with the largest throughput in northern China, which has the advantage of container transportation. Qinhuangdao Port is mainly dominated by coal transportation. Huanghua Port is the second export port of China's northern coal- Coal transportation; Tangshan Port, including Caofeidian Port and Jingtang Port, Caofeidian Port mainly transport crude oil, ore and coal. Jingtang port services in building materials, chemicals, metallurgy, containers etc. Compared with 2008, the throughput of port cargo in Beijing, Tianjin and Hebei region increased greatly in 2015, with the growth rates of Tangshan Port, Huanghua Port and Tianjin Port reaching 77.98\%, 52.43\% and 34.15\% respectively, but the throughput of Qinhuangdao Port increased only by $0.91 \%$, which has reached its design throughput capacity, as shown in TABLE 2.

Table 2. Beijing-Tianjin-Hebei port cargo throughput and growth rate Unit: million tons

\begin{tabular}{ccccc}
\hline Cargo throughput & Tianjin Port & Qinhuangdao Port & Huanghua Port & Tangshan Port \\
\hline 2008 & 35593 & 25081 & 7925 & 10853 \\
2015 & 54051 & 25309 & 16658 & 49285 \\
Growth rate & $34.15 \%$ & $0.91 \%$ & $52.43 \%$ & $77.98 \%$ \\
\hline
\end{tabular}

\subsection{Aviation Construction}

At present, Beijing, Tianjin and Hebei Airport Cluster has a total of eight airports, including Beijing Capital International Airport, Nanyuan International Airport, Tianjin Binhai Airport, Hebei Shijiazhuang Zhengding Airport, Zhangjiakou Ningyuan Airport, Tangshan Sannianhe Airport, Qinhuangdao Beidaihe Airport and Handan Airport. In 2015, the airport passenger throughput in the region reached 92.8826 million, accounting for $21.3 \%$ of the national civil aviation throughput. In 2015, Capital International Airport's passenger throughput reached 899.93 million, ranking the first in Asia and the second in the world. In addition, the new airport under construction in Beijing is positioned as a large-scale international aviation integrated transportation hub, which will effectively alleviate the problem of insufficient resources and promote interoperability in the air. 


\section{The Current Situation of Transportation Service}

In 2015, the "Beijing-Tianjin-Hebei Collaborative Development Transportation Integration Plan" promulgated, indicating the Beijing-Tianjin-Hebei transport integration has entered a substantive stage of development. In 2015, the total passenger traffic volume in Beijing, Tianjin and Hebei reached 14,332.6 million, of which 699.24 million were from Beijing, 197.57 million from Tianjin and 536.27 million from Hebei, down by $5.94 \%$, down $2.5 \%$, up $0.9 \%$ and down by $12.17 \%$ respectively. With the adjustment of transport structure and the development of civil aviation industry, the proportion of passenger traffic between the three places of Beijing, Tianjin and Hebei dropped, while the proportion of passenger traffic of railways and civil aviation continued to rise, with the largest increase in Tianjin, indicating that the pressure on Beijing's passenger hubs was relieved some achievements, as shown in TABLE 3.

Table 3. Passenger volume and growth rate of Beijing-Tianjin-Hebei region

\begin{tabular}{cccccccccccccc}
\hline \multicolumn{3}{c}{ Region } & \multicolumn{3}{c}{ Passenger traffic in $\mathbf{2 0 1 4}$ / million } & \multicolumn{3}{c}{ Passenger traffic in $\mathbf{2 0 1 5} /$ million } & \multicolumn{4}{c}{ growth rate/\% } \\
& highway & railway & $\begin{array}{c}\text { civil } \\
\text { aviation }\end{array}$ & total & highway & railway & $\begin{array}{c}\text { civil } \\
\text { aviation }\end{array}$ & total & highway & railway & $\begin{array}{c}\text { civil } \\
\text { aviation }\end{array}$ & total \\
\hline Beijing & 52354 & 12609 & 6752 & 71715 & 49931 & 12821 & 7172 & 69924 & -4.63 & 1.68 & 6.22 & -2.50 \\
Tianjin & 14530 & 3686 & 1382 & 19598 & 14218 & 4054 & 1503 & 19775 & -2.15 & 9.98 & 8.76 & 0.90 \\
Hebei & 51151 & 9571 & 338 & 61060 & 43563 & 9706 & 358 & 53627 & -14.83 & 1.41 & 5.92 & -12.17 \\
B-T-H & 118035 & 25866 & 8472 & 152373 & 107712 & 26581 & 9033 & 143326 & -8.75 & 2.76 & 6.62 & -5.94 \\
\hline
\end{tabular}

In terms of cargo volume, Beijing, Tianjin and Hebei region in 2015 completed 3.0332 trillion tons, down 3.31\% from 2014, of which Tianjin increased by $4.54 \%$ while that of Beijing and Hebei both decreased negatively by $4.48 \%$ and $2.58 \%$ respectively. The rapid development of railways and water transport in the three areas has shown a trend of increase in freight volume and greatly enhanced the status of freight transport. With the development of ports in Hebei Province, the volume of water transport in Hebei Province has risen sharply, an increase of $12.4 \%$ over 2014, which has a certain impact on the freight volume of Tianjin Port. In addition, the decrease in the freight volume of highways shows that the dependence of the Beijing, Tianjin and Hebei region on highways has been reduced and the transport structure has been improved.

Table 4. Cargo volume and growth rate of Beijing-Tianjin-Hebei

\begin{tabular}{|c|c|c|c|c|c|c|c|c|c|c|c|c|}
\hline \multirow[b]{2}{*}{ Region } & \multicolumn{4}{|c|}{ Freight volume in 2014 / tons } & \multicolumn{4}{|c|}{ Freight volume in 2014 / tons } & \multicolumn{4}{|c|}{ Growth rate/\% } \\
\hline & Highway & Railway & $\begin{array}{l}\text { Water } \\
\text { transport }\end{array}$ & Total & Highway & Railway & $\begin{array}{l}\text { Water } \\
\text { transport }\end{array}$ & Total & Highway & Railway & $\begin{array}{c}\text { Water } \\
\text { transport }\end{array}$ & Total \\
\hline Beijing & 25416 & 1132 & 0 & 26548 & 19044 & 1004 & 0 & 20048 & -25.07 & -11.31 & 0.00 & -24.48 \\
\hline Tianjin & 31130 & 8872 & 9749 & 49751 & 33724 & 8377 & 9910 & 52011 & 8.33 & -5.58 & 1.65 & 4.54 \\
\hline Hebei & 185286 & 48063 & 4041 & 237390 & 175637 & 51082 & 4542 & 231261 & -5.21 & 6.28 & 12.4 & -2.58 \\
\hline B-T-H & 241832 & 58067 & 13790 & 313689 & 228405 & 60463 & 14452 & 303320 & -5.55 & 4.13 & 4.80 & -3.31 \\
\hline
\end{tabular}

\section{The Current Situation of Transport Integration}

In 2014, the Beijing, Tianjin and Hebei region has realized the electronic non-parking fee (ETC), and the expressway is more convenient. At present, some of the 13 cities in the Beijing, Tianjin and Hebei region have been covered by the Beijing-Tianjin-Hebei transport card system and the Beijing, Tianjin and Hebei region covering 119 bus routes. The Beijing rail transit will achieve full coverage of the Beijing-Tianjin-Hebei Card by the end of 2017. To achieve cardholder connectivity is an important breakthrough in promoting the coordinated development of Beijing, Tianjin and Hebei. Many "broken head roads" and "bottlenecks" opened to traffic and promoted the integration of the three markets. By the year 2017, the "bottleneck road" of the seven general provincial highways has all been opened up.

In terms of rail transit construction, in 2017, Jingtang and Jingbin Railway started operation. In addition, Jingba Railway, Chongli Railway, Beijing Airport Intercity Railway Link Line, Langfang- 
Zhuozhou Intercity Railway, Ring Beijing Intercity Railway Langfang-Pinggu Section , Beijing to Shijiazhuang intercity railway, Gu'an to Baoding intercity railway projects are also being promoted in an orderly way.

\section{The Problems of Beijing-Tianjin-Hebei Transportation Development}

\subsection{The Traffic Network Layout is Irrational, and the Distribution of Transportation Functions is Not Balanced}

The Beijing, Tianjin and Hebei region, a radiated integrated traffic network centered in Beijing, has increased the unbalance distribution of traffic in three areas. Due to lack of interconnection between central cities and other cities in the region and lack of direct mode of transportation,it needs to transit through Beijing, increasing the transit traffic pressure of Beijing hub, while the transport hub functions of Tianjin and Hebei have not been effectively played. In addition, there is a lack of convenient traffic links between various modes of transport, resulting in inefficient traffic transfer.

7.2 The Transportation Structure is Not Reasonable, and the Passenger and Freight Transportation Mainly Depends on the Highway

From The Perspective of passenger and freight transport, passenger and freight transport in Beijing, Tianjin and Hebei mainly rely on highways, and the intensive railway transportation accounts for a relatively small proportion. In terms of passenger transport, the proportion of passenger traffic borne by the highway is too high, reaching $90.04 \%$ in 2011 and only $7.44 \%$ in the railway, an unreasonable proportion. However, with the adjustment of traffic-related policies, the proportion of the total amount of passenger traffic borne by the road has been on the downward trend, and the proportion of passenger traffic borne by railways and airlines has been on the increase. In terms of freight transportation, the proportion of freight carried by the highway is on an overall upward trend, the railway generally shows a downward trend, and the proportion of railways has increased in 2014; the trend of aviation changes is relatively stable and the contribution of freight traffic is small while the proportion of waterborne transport is on the rise, as shown in TABLE 5.

Table 5. The proportion of passenger and cargo transportation modes

\begin{tabular}{|c|c|c|c|c|c|c|c|}
\hline \multirow{2}{*}{ Year } & \multicolumn{3}{|c|}{$\begin{array}{c}\text { Undertake the proportion of passenger } \\
\text { volume(\%) }\end{array}$} & \multicolumn{4}{|c|}{$\begin{array}{c}\text { Undertake the proportion of freight } \\
\text { Volume(\%) }\end{array}$} \\
\hline & Highway & Railway & Civil aviation & Highway & Railway & Civil aviation & Water transport \\
\hline 2011 & 90.04 & 7.44 & 2.51 & 76.41 & 18.03 & 0.05 & 5.51 \\
\hline 2012 & 89.82 & 7.47 & 2.71 & 79.12 & 16.73 & 0.04 & 4.11 \\
\hline 2013 & 84.19 & 11.64 & 4.16 & 79.66 & 16.79 & 0.05 & 3.52 \\
\hline 2014 & 77.46 & 16.98 & 5.56 & 77.05 & 18.50 & 0.05 & 4.39 \\
\hline 2015 & 75.15 & 18.55 & 6.30 & 84.52 & 10.07 & 0.06 & 5.35 \\
\hline
\end{tabular}

7.3 The Utilization of the Airport Resources is Not High, and the Cooperative Development Needs to Be Strengthened

The airport cluster in the Beijing, Tianjin and Hebei region is extremely unbalanced in development and faces the problem of uneven distribution of resources. The Capital International Airport's passenger throughput of 899.93 million passengers, the capacity is close to saturation; Tianjin airport throughput capacity of 50 million, but the actual only 14.31 million, capacity utilization efficiency of only 28\%; Shijiazhuang Zhengding airport throughput capacity of 20 million people, the actual Passenger throughput 5.98 million, capacity utilization efficiency is only $30 \%$. The airport resources in Tianjin and Shijiazhuang have not been effectively utilized, and the diversion effect for the capital airport is not obvious.

\section{Conclusion and Suggestion}

Beijing Tianjin Hebei regional comprehensive transportation network has basically formed. The future traffic integration of the Beijing, Tianjin and Hebei region is not a large-scale infrastructure construction. Rather, it will be based on the original transport network to integrate and crack the non- 
integrated issues of development. In view of the problems existing in the process of Beijing-TianjinHebei traffic integration, the following countermeasures and suggestions are put forward.

\subsection{Establish a Comprehensive Transport Network for Multi-Modal Transport and Connectivity}

Under the guidance of "the Beijing-Tianjin-Hebei Collaborative Transportation Integration Plan", we will speed up the construction of multi-center and inter-connected network-type comprehensive transportation network. By improving the external traffic routes, adjusting routes and increasing train departure frequency, we will enhance the status of Tianjin and Shijiazhuang's traffic network center and further ease the traffic pressure on Beijing. In addition, aiming at the problem of poor connection between various transport modes, it is necessary to vigorously develop multi-modal transport and strengthen the connection between airports, highways, railways and ports. On the one hand, we will further promote the joint transport of air and iron, and promote the development of the three airports. On the other hand, the port consolidation and transportation system should be strengthened and the railway freight transport should be vigorously developed so as to improve the current situation of road-based distribution in Beijing, Tianjin and Hebei. On the basis of the existing Daqin Railway, Shuo Huang Railway, Luan-Hong Kong Railway and Caofeidian Port Area Railway, we should continue to optimize its expansion capacity and build a modern integrated transportation system.

\subsection{Optimize the Transportation Structure and Orderly Construction of Beijing, Tianjin and Hebei on the Track}

With the promotion of the coordinated development of Beijing, Tianjin and Hebei, the connection between the three places have become increasingly closer, and the demand for passenger and freight transport has increased. However, the increase in the demand for passenger and freight transport needs support from the transport supply. Therefore, it is necessary to speed up the construction of the four-level rail transit network of the national trunk railway, inter-city railway, suburban railway and urban subway in Beijing, Tianjin and Hebei [17]. Through the trunk railways to strengthen the contact of major cities in the region, inter-city railways and suburban railways to meet the business travel, daily commuter travel needs, urban metro service in the central city and the main urban areas, to meet different travel needs of different passenger characteristics, to achieve multi-level Orbit integration. However, the development of inter-city railways and suburban railways in the region lags far behind and is far from meeting the requirements for efficient, convenient and environmentally-friendly passenger transportation. Therefore, according to the characteristics of passenger demand in the region, the inter-city railways and suburban railways should be built orderly driven along the development of towns and cities.

\subsection{Integration of Airport Resources of The Three Places to Achieve Differentiated and Coordinated Development}

In order to solve the uneven distribution of Beijing-Tianjin-Hebei airport resources and unbalanced business development, it is necessary to make reasonable positioning of the airports in Beijing, Tianjin and Hebei, foster strengths and circumvent weaknesses, and realize the coordinated development of differentiation, thus relieving the capital international airport is not international hub function, Tianjin and Shijiazhuang airport positive definite airport further undertaking of Beijing organization resources, dislocation of the respective advantages and mutual construction of BeijingTianjin-Hebei regional aviation market. Among them, Capital International Airport and Capital Airport II are the international complex hubs and domestic hubs, respectively focusing on international and domestic air transport services. Beijing Nanyuan Airport mainly relieves the pressure on Capital International Airport. Tianjin Binhai Airport focuses on air cargo services and domestic routes and passenger charter flights in Asia, with the function of being the freight center in northern China. Shijiazhuang Zhengding Airport mainly operates the passenger transport, low-cost airlines and transit businesses in the second and third tier cities in China. It is the major diversion and standby airport in Beijing and Tianjin. It is connected with the branches of Tangshan Sannvhe Airport, Qinhuangdao Shanhaiguan Airport, Zhangjiakou Ningyuan Airport and Handan Airport Airport together to create a rational structure, balanced layout, a clear division of labor in the Beijing-TianjinHebei multi-purpose airport system. 


\section{Acknowledgements}

This research was financially supported by Beijing philosophy and social science planning project (Project No. 17GLA084).

\section{References}

[1]. Zheng Q C ,Zhao D Y, Guo S P, et al. The influence of traffic integration on regional economic development under the background of coordinated development of Beijing, Tianjin and Hebei[J]. Logistics Technology, 2017.

[2]. Zhang G W. Beijing-Tianjin-Hebei Integrated Traffic Integration and Synergy Development The 35th Meeting of "Transport $7+1$ Forum"[J]. Urban Management Science\&Technology, 2014.

[3]. Pang S H. The current situation and main problems of traffic integration in Beijing, Tianjin and Hebei[J]. Urban Management Science\&Technology, 2015.

[4]. Shi Z H. Strategic Thinking of Beijing - Tianjin - Hebei Transport Integration Planning[J]. Journal of Beijing Jiao tong University, 2016.

[5]. Wang Z H. Promoting the coordinated development of Beijing, Tianjin and Hebei with the integration of traffi[J]. Macroeconomic Management, 2015.

[6]. Zheng X, Zhao H Q. Analysis of problems and solutions in the coordination of traffic planning in Beijing, Tianjin and Hebei[J]. The Freind of Leaders, 2017.

[7]. Zhao H. The core and key problems of the coordinated development of Beijing, Tianjin and Hebei[J]. China Business and Market,2014.

[8]. Chen S D. Traffic integration in Beijing, Tianjin and Hebei[J]. China Transportation Review, 2015.

[9]. Quan B, Chen S. Reflections on the Transformation of Beijing Transportation Development Model under the Integration of Beijing, Tianjin and Hebei[J]. Urban Planning Forum, 2016.

[10]. Quan B, Li X. Research on Tianjin regional traffic development strategy oriented to Beijing Tianjin Hebei[J]. Urban Planning Forum, 2014.

[11]. Yao S Y, Hu Y, Chai R Z. Research on the development strategy of Hebei transportation support system oriented to the integration of Beijing, Tianjin and Hebei[C]. Forum on environment and development,2014.

[12]. Zheng J. Accelerate the railway construction and boost the traffic integration in Beijing, Tianjin and Hebei[J]. Urban Mass Transit,2014.

[13]. Yuan T, Xu Z. Research on highway traffic development in Tianjin under the coordination strategy of Beijing, Tianjin and Hebei[J]. City,2015.

[14]. Wu T S. Research on the Countermeasures of Aeronautical transportation integration in Beijing, Tianjin and Hebei region[C].2014 Beijing-Tianjin-Hebei Synergy Symposium,2014.

[15]. Sun M Z, Yu L, Guo J F, et al. Research on the problems and Countermeasures of the integrated development of traffic in Beijing, Tianjin and Hebei[J]. Urban Transport of China, 2016.

[16]. Bi L L. Discussion on the change of statistical caliber of traffic volume statistics and the method of calculation[J]. Jiangsu Transportation Research,2015.

[17]. Wang H, Li Z P. The realization path of the integration of the cross regional rail transit in Beijing, Tianjin and Hebei[J].Hebei Academic Journal,2015. 